\title{
Discrepancies in Perceptions of Close Relationships of Young Adolescents: A Risk for Psychopathology?
}

\author{
Jantine L. Spilt • Pol A. C. Van Lier • \\ Susan J. T. Branje · Wim Meeus · Hans M. Koot
}

Received: 10 September 2014/ Accepted: 19 November 2014/Published online: 2 December 2014

(C) Springer Science+Business Media New York 2014

\begin{abstract}
Discrepancies between children and partners (e.g., parents, friends, peers) in reports of social functioning and self-other relationships are common in clinical practice and in research. However, it is not clear whether children's biased perceptions of self-other relationships, relative to the reports of partners, are predominantly a reflection of underlying psychological dysfunctions or whether these biased perceptions present a risk factor for subsequent problematic development. This longitudinal study therefore examined the effects of adolescent-mother disagreement and adolescent-best friend disagreement in perceptions of close (dyadic) relationships on the development of psychopathology in early adolescence. The sample included 497 thirteen year-old adolescents of Dutch-Caucasian backgrounds (57\% boys; $41 \%$ at high risk for externalizing problems), their mothers, and selfnominated best friends. The participants completed reports of positive dyadic relationship quality (warmth) in Grade 7.
\end{abstract}

\footnotetext{
J. L. Spilt ( $₫)$

Faculty of Psychology and Education, Research Unit School Psychology and Child and Adolescent Development, Katholieke Universiteit Leuven, Tiensestraat 102, Box 3717, 3000 Louvain, Belgium

e-mail: Jantine.Spilt@ppw.kuleuven.be
}

J. L. Spilt · P. A. C. Van Lier - H. M. Koot

Department of Developmental Psychology, EMGO Institute for Health and Care Research, VU University, Amsterdam, The Netherlands

\section{S. J. T. Branje · W. Meeus}

Research Centre for Adolescent Development, Utrecht

University, Utrecht, The Netherlands

W. Meeus

Department of Developmental Psychology, Tilburg University, Tilburg, The Netherlands
Discrepancy scores were based on difference scores between the adolescents' versus the partners' reports. Both absolute disagreement and direction of disagreement (i.e., over- or underestimation relative to the relationship partner) were examined. Self-reported symptoms of depression and mother-reported aggression were assessed in Grade 7, 8, and 9. Absolute disagreement in perceptions of warmth between adolescents and best friends was significantly related to higher baseline levels of aggression. No significant effects of discrepancy scores on growth curves of symptoms of depression and aggression were found. The results may suggest that it is more important for adolescents to develop positive perceptions of close relationships than to agree with partners on the quality of the relationship.

Keywords Psychopathology - Close relationships . Informant discrepancies - Early adolescence

\section{Introduction}

Discrepancies between informants in reports on children's behavioral and social functioning are common in clinical practice and research. Such informant discrepancies are not just nuisance but represent meaningful information that in itself could be a marker of problematic development (De Los Reyes 2011). Discrepant self-evaluations and selfother evaluations of children and adolescents, relative to the reports of others (e.g., parents, teachers, peers), have been related to psychological dysfunctions including depressive symptoms and aggression (e.g., Cole et al. 1998; Edens et al. 1999; Ehrlich et al. 2013; Hoffman et al. 2000). As such, the correction of biased perceptions of children and adolescents may be an important focus of clinical 
treatment. However, it is currently unknown whether discrepant relationship perceptions are a risk factor for the development of adolescent psychopathology rather than a marker or reflection of psychopathology.

This study addresses two gaps in the literature on biased self and self-other perceptions and problematic development. First, most research in this area has focused on discrepant views of children concerning assessments of child psychopathology (De Los Reyes and Kazdin 2005, competencies (e.g., Hoffman et al. 2000; Hoza et al. 2010), and social acceptance (e.g., Brendgen et al. 2004; Kistner et al. 2006). Surprisingly little is known about the developmental consequences of discrepant views between children and interaction partners concerning the quality of close dyadic relationships (e.g., parent-child relationships, friendships). Second, there is a lack of longitudinal studies that have examined the effects of discrepant perceptions of social relationships on psychopathology while controlling for cross-sectional associations between discrepant perceptions and baseline levels of psychopathology. It is thus unclear whether biased self and self-other perceptions are only a reflection of underlying psychological dysfunctions or present a risk for the development of psychopathology above and beyond initial levels of psychopathology. To address these limitations, this longitudinal study examined discrepant perceptions of dyadic relationship quality between young adolescents and their mothers and best friends.

\section{Do Discrepancies in Self-other Perceptions Predict Problematic Development?}

Highly positive but discrepant self-perceptions may reflect a tendency to protect one-self against negative feedback from the social environment. This defensive coping style is also referred to as the positive illusionary bias or the selfenhancement bias. A self-enhancement bias has often been observed among aggressive children and children with ADHD (David and Kistner 2000; Hoza et al. 2010; Ohan and Johnston 2011; Owens et al. 2007; Scholtens et al. 2012; but for an exception, see Ekornås et al. 2011). One explanation for a self-enhancement bias is that idealized views of the self and self-other relationships protect these children against negative emotions associated with social failure and frequent disconfirmation of the self, due to low competencies or aggressive coping styles (Hoza et al. 2010; Ohan and Johnston 2011; Hughes et al. 1997).

Baumeister et al. (1996) have posited that inflated perceptions and feelings of superiority are a cause of aggression and violence. The self-esteem of children with unrealistically-high self and self-other perceptions may be extra vulnerable to negative feedback from others. When unrealistically-high self and self-other perceptions are challenged or disputed by others, children may respond in an angry and hostile way in order to defend their threatened ego. In addition, exaggerated self and self-other perceptions may be associated with a reduced capacity for selfreflection and a reluctance to change behaviors and attitudes in response to corrective feedback.

In support of these claims, DuBois and Silverthorn (2004) found that inflated perceptions of social competence (as compared to parents' ratings) predicted increases in externalizing problems over a one-year period in early adolescence. Moreover, there is evidence that inflated perceptions of social acceptance predict increases in aggression particularly for socially rejected children (Orobio de Castro et al. 2007) and aggressive children (Brendgen et al. 2004). However, inflated perceptions of competence in the social domain (relative to parents' reports) did not predict the development of aggression in the strongly-designed longitudinal study by Hoza et al. (2010).

Further contributing to the mixed evidence base for the developmental risks of inflated self- and self-other perceptions are longitudinal studies that have found positive effects, rather than negative effects, in the general population (Brendgen et al. 2004; Kistner et al. 2007). For instance, research has suggested that inflated perceptions may protect children against the development of depressive symptoms (Brendgen et al. 2004; Hoza et al. 2010; Whitton et al. 2008). However, the already cited longitudinal study by Hoza et al. (2010) did not support this idea: Decreases in depressive symptoms were found to predict decreases in positive biases rather than vice versa.

Moreover, the reversed link, that is that inflated selfperceptions may lead to depression, has also been suggested. Based on self-verification theory (Swann 1983), it has been hypothesized that social feedback that disconfirms children's self-views causes mental distress, irrespective of whether these self-views are inflated or deflated (Joiner et al. 2006; Kistner et al. 2006). Consistent with this proposition, inflated self- and self-other perceptions have been found predictive of increases in depressive symptoms (DuBois and Silverthorn 2004; Joiner et al. 2006; Kistner et al. 2006).

Negatively-biased perceptions of the self and self-other relationships have also been linked to depressogenic cognitive styles (Beck 1967; Cole et al. 1998; Ekornås et al. 2011; Hoffman et al. 2000; Kistner et al. 2006; Whitton et al. 2008). Although the exact processes are unclear, negatively-biased self and self-other evaluations may result from an attentional bias and a memory bias for negative information relative to positive information (Jacobs et al. 2008). Recent findings demonstrate that underestimations of social acceptance, quality of parenting, and parent-child relationship quality are associated with heightened levels 
of depressive symptoms (Ehrlich et al. 2013; Reidler and Swenson 2012). However, few longitudinal studies have been conducted to test whether negatively-biased self- and self-other perceptions can predict increases in depressive symptoms (Jacobs et al. 2008) and the results of these few studies have been mixed. Several short-term longitudinal studies have found negatively-biased perceptions of social acceptance predictive of increases in depressive symptoms in middle childhood (Brendgen et al. 2004; Kistner et al. 2006). However, the research of Cole et al. (1998) across different grades suggested that negatively-biased self-perceptions are a symptom of depression rather than a predictor of depression. In addition, underestimations of friendship quality relative to friends' reports have not been found predictive of depressive symptoms when initial levels of depressive symptoms were controlled for (Brendgen et al. 2004).

Most of the research cited above was focused on biased perceptions of social competencies and (peer) acceptance. There is much less longitudinal research on the developmental significance of discrepant views of children on parent-child relationships and parenting quality relative to parents' views. Recent longitudinal research indicates that discrepant views on parenting behavior between children and their mothers are predictive of depressive symptoms 1 year later while controlling for child suicidal behavior (Guion et al. 2009). However, no effects on externalizing problems were found when controlling for baseline levels of externalizing behavior. In addition, the analytic model did not control for concurrent associations between discrepancy views and psychopathology. In line with selfverification theory, DuBois and Silverthorn (2004) found both positively- and negatively-biased perceptions of family competence of young adolescents predictive of internalizing and externalizing problems one year later.

\section{Challenges in Research on Discrepancies in Relationship Perceptions}

When studying perceptions of dyadic relationships, it is not possible to distinguish between truly accurate and inaccurate perceptions of the relationship. Perceptions of dyadic relationships are subjective in nature. This implies for example that overestimation of warmth and support by the adolescent, relative to the interaction partner, can reflect self-enhancement of the adolescent but at the same time could result from underestimation by the interaction partner. The use of reports of outsiders does not provide a satisfactory solution to this issue. Outsiders can perhaps observe interactions and communication between relationship partners but these are only proxies of relationship quality at best. Consequently, researchers have argued that the meaning of discrepant perceptions can only be understood on the basis of a variety of studies using different conceptualizations of discrepancies and methods (e.g., Reidler and Swenson 2012). To address this issue as much as possible, we studied two different types of close (dyadic) relationships, that is the mother-child relationship and the adolescent-best friend relationship.

A further complicating issue in research on discrepant perceptions is the conceptualization of discrepancy. Studies have used single difference scores between the subject's perceptions and the partner, with lower scores representing underestimation and higher scores representing overestimation (e.g., Guion et al. 2009; Hoza et al. 2010). However, an examination of difference scores while ignoring the direction of disagreement hinders the interpretation of the results. For example, when a positive association is found between the difference score and the outcome, for instance aggression, it is not known whether this means that overestimations are associated with higher levels of aggression or whether underestimations are associated with lower levels of aggression, or both. Scholars therefore have emphasized the need to distinguish between absolute levels of disagreement and direction of disagreement (Ehrlich et al. 2013; Gaylord et al. 2003; Kistner et al. 2006).

\section{Present Study}

It is not known if and to what extent incongruence in perceptions of dyadic relationships between young adolescents and their interaction partners constitute a risk factor for problematic development. Research on the significance of discrepant perceptions has been cross-sectional or has failed to appropriately control for initial levels of psychopathology and concurrent associations between discrepant perceptions and psychopathology (for an exception see e.g., Hoza et al. 2010). Moreover, there are few, if any, longitudinal studies that have examined the developmental consequences of discrepant perceptions of close (dyadic) relationships between adolescents and their interaction partners. Therefore, this three-wave study examined the effects of discrepant views of adolescents in relationships with mothers and with best friends.

We tested the hypothesis that discrepant perceptions of warmth predict growth in psychopathology from adolescent age 13-15. We hypothesized that (1) overestimations of warmth, relative to interaction partners, would be predictive of increases in aggression (Baumeister 1989; Baumeister et al. 1996), and that (2) underestimations of warmth represent a cognitive vulnerability factor predicting the development of depressive symptoms (Jacobs et al. 2008). In addition, guided by self-verification theory, we also hypothesized a predictive effect of overestimations of warmth on growth in depressive symptoms (DuBois and Silverthorn 2004; Joiner et al. 2006; Kistner et al. 2006). 
Finally, we expected more extreme over- or underestimation to be related to greater levels of impairment. To test this assumption, we examined interactional effects between absolute levels of disagreement and the direction of disagreement (cf. Gaylord et al. 2003).

\section{Method}

Sample

Participants were involved in the ongoing longitudinal research project "research on adolescents development and relationships" (RADAR). In the RADAR study, young adolescents at risk for externalizing problems were oversampled. In a first step, teachers' reports of behavior problems were collected for 5,150 young adolescents using the teacher's report form (TRF; Achenbach 1991). Young adolescents with $\mathrm{T}$-scores $\geq 60$ were considered at high risk for externalizing problems. In a second step, young adolescents, their families, and best friends were included who fitted the inclusion criteria: only full families (adolescent, mother, father, sibling $>10$ years) fluent in Dutch language were eligible for participation $(n=1,081)$. Of these 1,081 families, 470 refused actively and 114 did not sign informed consent. Written consent was obtained for 497 Dutch-Caucasian families including 291 young adolescents at low to medium risk and 206 young adolescents at high risk for externalizing problems. There were no significant differences in TRF externalizing scores between included and excluded adolescents in the control subsample $(p=.88)$ and also not in the high risk subsample $(p=.16)$. From the 497 families, $6.2 \%$ dropped out at Wave 2 and $4.6 \%$ dropped out at Wave 3, suggesting low rates of study attrition.

Adolescents were asked to invite his or her best friend to participate in the study. Parents of these friends were requested to provide written consent. At Wave 1, 446 best friends participated. In the low-risk subsample, the percentage of participating best friends was $95.2 \%$. This percentage was significantly higher than the percentage of participating friends in the high-risk subsample, which was $81.1 \%(p<.001)$. Previous research with the same sample has reported relatively high levels of stability and reciprocity in these friendships (Defoe et al. 2013; Keijsers et al. 2012).

At Wave 1, adolescents (57\% boys) were on average 13 years old $(S D=.52)$, self-nominated best friends (56\% boys) were also 13 years old $(S D=.80)$, and mothers were on average 44 years old $(S D=4.45)$. A minority of adolescents $(11 \%)$ came from families with low socio-economic status (Statistics-Netherlands 1993).

The study was approved by the medical-ethical committee of Utrecht University, The Netherlands. For more details about the sample characteristics and selection procedure, see Van Lier et al. (2011).

Procedure

Trained research assistants visited the respondents (including the target adolescent, mother, best friend) at home to administer the questionnaires. Visits were scheduled annually between January and March. Questionnaires were filled out by the participants. Both written instructions and verbal instructions from the interviewers were provided. Assessment time was about $3 \mathrm{~h}$ for the adolescents and their parents (including interaction tasks that were not part of this study) and for best friends between 1 and $1.5 \mathrm{~h}$.

Relationship reports were assessed in Grade 7 (Wave 1). Symptoms of depression and aggression were assessed annually at age 13 (Wave 1), age 14 (Wave 2), and age 15 years (Wave 3 ).

Instruments

\section{Perceived Dyadic Relationship Quality}

Relationship quality was measured with the subscale support/warmth of the Network of Relationship Inventory (NRI; Furman and Buhrmester 1985). The subscale consists of eight items rated on a 5 point Likert scale $(1=\mathrm{a}$ little or not at all; $5=$ more is not possible). Adolescents rated their relationship with their best friend (e.g., "How much does your best friend care about you"; $\alpha=.86$ ) and their mother (e.g., "How much does your mother care about you"; $\alpha=.78$ ). In addition, best friends (e.g., "How much does your best friend care about you"; $\alpha=.82$ ) and mothers (e.g., "How much does your child care about you"; $\alpha=.71$ ) rated the relationship quality with the adolescent. The NRI is a widely-used measure for the assessment of close (dyadic) relationships with parents, teachers, and friends, and has adequate psychometric properties (e.g., Edens et al. 1999).

\section{Calculation of Discrepancy Scores}

First, the partner's scores were subtracted from the adolescent's scores such that positive scores indicated overestimation and negative scores indicated underestimation relative to the interaction partner. Second, positive scores were multiplied with 1 and the negative scores with -1 to obtain a measure of Absolute disagreement (irrespective of the direction of the disagreement). To obtain a measure of the Direction of disagreement, a dummy variable representing overestimation (1) and underestimation (0) was created. Difference scores of .00 and higher were rated as overestimation and difference scores below .00 were rated 
as underestimation. Finally, the interaction term was computed by multiplying absolute disagreement with the dummy score of direction of disagreement.

\section{Depressive Symptoms}

Reynolds Adolescent Depression Scale (RADS; Reynolds 2002) was used to measure adolescent-reported symptoms of depression. The total scale comprises 23 items (e.g., "I am sad") rated on a 4 point scale $(1=$ almost never; $4=$ often) for which mean scores were calculated ( $\alpha=.93-.94)$. The RADS has proven a reliable and valid tool for the assessment of depressive symptoms of young adolescents (Reynolds and Mazza 1998).

\section{Aggression}

Mothers completed the aggression subscale of the Child Behavior Checklist/4-18 (CBCL; Achenbach 1991). The scale comprises 18 items, rated on a 3-point scale ranging from $0=$ never to $2=$ often (e.g., "Fights"; "Has temper tantrums"), for which mean scores were calculated $(\alpha s=.90)$. The CBCL is a widely-used assessment tool with well-evaluated psychometric properties (e.g., De Groot et al. 1994; Verhulst et al. 1996).

\section{Statistical Analyses}

Using latent growth modelling (LGM), linear growth curves for symptoms of depression and aggression from Wave 1 to Wave 3 were fitted by specifying a model with latent variables or growth factors representing intercept and slope for each outcome. LGM was conducted in Mplus (Muthén and Muthén 1998-2011) using full information maximum likelihood estimation to account for missing data. The covariance coverage (i.e., the proportion of values present) ranged between .90 and .99 across all data points.

Growth curves for depressive symptoms and aggression were estimated in the same model while controlling for gender and SES. The slope estimates were regressed on the discrepancy variables in order to test the hypothesis that discrepancy views contribute to growth in psychopathology. In addition, intercept levels were allowed to correlate with the discrepancy variables. Intercept and slope estimates were also regressed on the dummy variables gender (Boy) and SES (Low SES). The significance of parameter estimates was tested two-tailed. Non-significant interaction terms were removed from the model to estimate main effects (Table 3).

Depressive symptoms and aggression showed moderate non-normality with skewness values $\leq 1.4$ and kurtosis values $\leq 2$. The MLR estimator was used to evaluate model fit because this estimator is robust to moderate non-normality. Model fit was considered satisfactory with confirmatory fit index $(\mathrm{CFI}) \geq .95$, standardized root mean square residual (SRMR) $\leq .08$, and root mean square error of approximation (RMSEA) $\leq .06$ (Hu and Bentler 1999). Outliers $(n=3)$ were identified based on consistently high scores on three influence statistics: Influence $(>3)$, Cook's distance $(>4.5)$, and Mahalanobis distance $(>50)$. Eight cases were excluded because of missing data on the independent variables.

\section{Results}

Preliminary Analyses and Descriptive Statistics

The descriptive statistics are presented in Tables 1 and 2 . Paired-sample $t$ tests revealed that, on average, adolescents reported higher levels of warmth than mothers $(t[490]=14.824, p<.001)$. Adolescents and best friends reported equally high levels of warmth $(t[442]=1.240$, $p=.22$ ).

A dual growth model for aggression and symptoms of depression without predictors was estimated first. The fit of the model was good $(\mathrm{CFI}=.99 ; \quad \mathrm{SRMR}=.02$; RMSEA $=.05)$. The intercept of depressive symptoms was $1.68(S E=.03, p<.001)$ and the intercept of aggression was $.39(S E=.03, p<.001)$. Both slopes were non-significant (depression: $B=.02, S E=.02, p=.44$; aggression: $B=-.01, \quad S E=.01, \quad p=.28)$, indicating stable group-mean levels of symptoms of depression and aggression across early adolescence. Gender (boy) was a significant negative predictor of intercept $(B=-.16$, $S E=.04, p<.001)$ and slope $(B=-.10, S E=.02$, $p<.001$ ) of depressive symptoms indicating lower overall means for boys. Gender did not predict growth curve parameters of aggression (intercept: $B=.01, S E=.03$, $p=.78$; slope: $B=-.01, S E=.01, p=.38)$. Low SES predicted higher intercept levels of aggression $(B=.18$, $S E=.06, p<.01)$. The effect of low SES on intercept levels of symptoms of depression was marginally significant $(B=.13, S E=.07, p=.09)$. SES and gender were included in all subsequent models.

\section{Results for Adolescent-Best Friend Disagreement}

\section{Correlational Analyses}

Correlation analyses suggested non-significant correlations between the discrepancy variables and symptoms of depression at all waves (Table 2). Absolute levels of disagreement between the adolescent and best friend and the interaction term absolute disagreement $\times$ direction of disagreement were positively correlated with aggression but 
Table 1 Descriptive statistics of participants' reports of warmth, depression, and aggression

\begin{tabular}{|c|c|c|c|c|c|c|c|c|c|c|c|}
\hline & $M$ & $S D$ & 1 & 2 & 3 & 4 & 5 & 6 & 7 & 8 & 9 \\
\hline 1. Warmth $\mathrm{AB}$ & 3.48 & 0.70 & & & & & & & & & \\
\hline 2. Warmth BA & 3.42 & 0.63 & $.37^{* *}$ & & & & & & & & \\
\hline 3. Warmth AM & 3.90 & 0.53 & $.41^{* *}$ & $.20^{* *}$ & & & & & & & \\
\hline 4. Warmth MA & 3.50 & 0.43 & .07 & .05 & $.26^{* *}$ & & & & & & \\
\hline 5. Depression W1 & 1.63 & 0.49 & $-.15^{* *}$ & -.06 & $-.29^{* *}$ & $-.12^{* *}$ & & & & & \\
\hline 6. Depression W2 & 1.50 & 0.50 & .00 & -.02 & $-.17^{* *}$ & -.08 & $.56^{* *}$ & & & & \\
\hline 7. Depression W3 & 1.53 & 0.52 & .08 & .02 & $-.19^{* *}$ & -.04 & $.54^{* *}$ & $.67^{* *}$ & & & \\
\hline 8. Aggression W1 & 0.41 & 0.35 & .04 & -.05 & $-.14^{* *}$ & $-.15^{* *}$ & $.26^{* *}$ & $.23^{* *}$ & $.23^{* *}$ & & \\
\hline 9. Aggression W2 & 0.41 & 0.35 & .00 & -.06 & $-.17^{* *}$ & $-.14^{* *}$ & $.23^{* *}$ & $.27^{* *}$ & $.24^{* *}$ & $.77^{* *}$ & \\
\hline 10. Aggression W3 & 0.37 & 0.34 & -.01 & -.06 & $-.11^{*}$ & $-.11^{*}$ & $.17^{* *}$ & $.23^{* *}$ & $.26^{* *}$ & $.72^{* *}$ & $.76^{* *}$ \\
\hline
\end{tabular}

$\mathrm{AB}$, Adolescents' reports about relationship with best friend; BA, Best friends' reports about relationship with adolescent; AM, Adolescents' reports about relationship with mother; MA, Mothers' reports about relationship with adolescent; W1, Grade 7; W2, Grade 8; W3, Grade 9

$* p<.05 ; * *<.01$ (two-tailed)

only at Wave 1 , suggesting that more extreme overestimations of warmth by the adolescent (relative to his/her best friend) were related to concurrent adolescent aggression.

\section{Latent Growth Models}

Next, we tested the predictive effects of the discrepancy variables on the growth curves of depression and aggression taking into account the effects of the adolescents' and partners' perceptions of warmth (Table 3). Discrepancy variables did not predict intercept and slope levels of depression. Higher adolescent perceptions of warmth but not best friends' perceptions of warmth predicted lower intercept levels of depression.

Furthermore, the absolute level of disagreement in perceptions between adolescents and their best friend predicted higher intercept (but not slope) levels of aggression. The direction of disagreement (i.e., over- or underestimation by the adolescent relative to his/her best friend) did not predict intercept or slope levels of aggression. Higher adolescent perceptions of warmth but not best friend perceptions of warmth predicted lower slope levels of aggression.

\section{Results for Adolescent-Mother Disagreement}

\section{Correlational Analyses}

Overestimations of warmth by the adolescent (relative to the mother's report) as indicated by the variable direction were associated with lower levels of depressive symptoms at Waves 1 and 2 (Table 2). Moreover, the interaction term absolute disagreement $\times$ direction of disagreement was negatively correlated with depressive symptoms at Wave 1, suggesting that more extreme overestimations of warmth by the adolescent were related to the lowest levels of concurrent symptoms of depression. Furthermore, we found non-significant correlations between the discrepancy variables and aggression at all waves.

\section{Latent Growth Models}

Discrepancy variables did not significantly predict intercept and slope levels of symptoms of depression (Table 3). Higher adolescent perceptions of warmth but not mother perceptions of warmth were associated with lower intercept levels of adolescent-reported symptoms of depression.

In addition, discrepancy variables did not significantly predict intercept and slope levels of aggression. Higher maternal perceptions of warmth but not adolescent perceptions of warmth were associated with lower intercept levels of mother-reported aggression.

\section{Discussion}

Informant discrepancies in the assessment of symptoms of child psychopathology and related constructs (e.g., social functioning) are considered a risk for the development of psychopathology (De Los Reyes 2011). Negatively-biased perceptions of the self and self-other relationships of children and adolescents, relative to the reports of others, have been associated with depression (e.g., Beck 1967; Cole et al. 1998; Ekornås et al. 2011; Hoffman et al. 2000; Joiner et al. 2006; Kistner et al. 2006; Whitton et al. 2008), whereas overly-positive perceptions have been associated with aggression (e.g., David and Kistner 2000; Hoza et al. 2010; Ohan and Johnston 2011; Owens et al. 2007; Scholtens et al. 2012). However, in comparison to research 


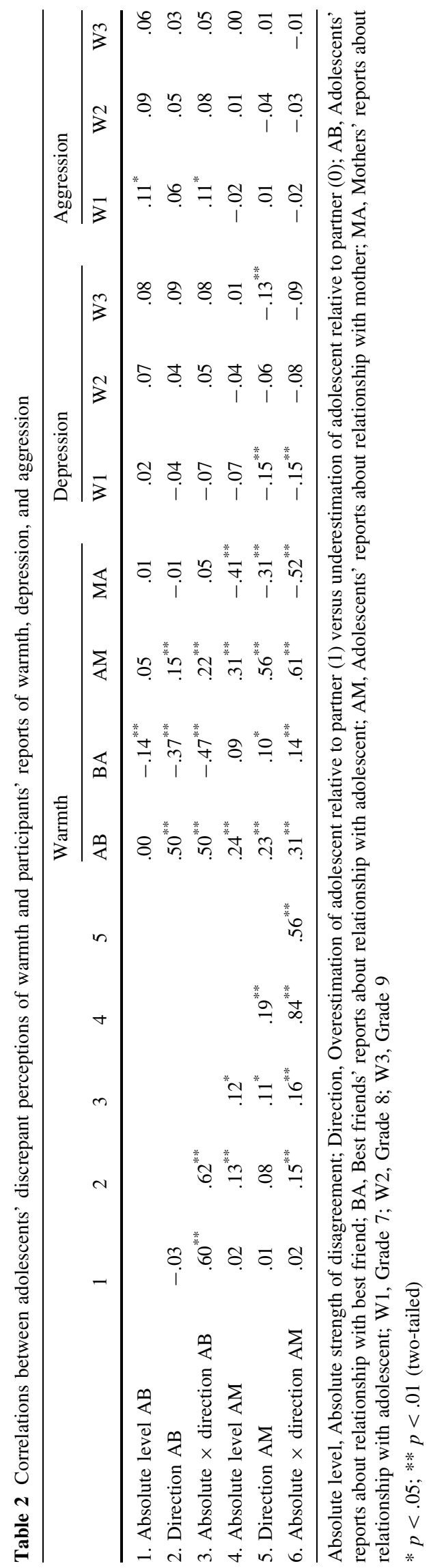

on discrepant perceptions of child symptoms, there has been relatively little research on biased self-other perceptions in the social domain (e.g., perceptions of social acceptance), whereas research on biased perceptions of dyadic relationships has been virtually absent. In addition, there is a lack of longitudinal studies that have examined long-term outcomes covering multiple years and a lack of longitudinal studies that have adequately controlled for initial levels of psychopathology and main effects of selfother perceptions on growth in psychopathology. Also, not all studies have taken into account the direction of disagreement (i.e., overestimation or underestimation of selfother perceptions relative to the reports of others), which hinders the interpretation of the results. Finally, it should be noted that the results from the few extant (short-term) longitudinal studies in the social domain that did control for cross-sectional associations between discrepant perceptions and psychopathology have been decidedly mixed. Some studies did find prospective effects of discrepant perceptions of peer acceptance on psychopathology (DuBois and Silverthorn 2004; Kistner et al. 2006), whereas other studies have yielded mixed results (Brendgen et al. 2004) or failed to find prospective effects (Cole et al. 1998; Hoza et al. 2010). A notable study on dyadic friendship quality in middle childhood indicates that overestimations of friendship quality contribute to growth aggression (but not symptoms of depression) over a 6-month period (Brendgen et al. 2004). In addition, there are no longitudinal studies that have examined discrepant perceptions in the context of parenting or the parent-child relationship that have adequately controlled for cross-sectional associations between discrepant perceptions and psychopathology or main effects. Consequently, it is currently not known whether discrepant perceptions of selfother relationships are simply a reflection of psychopathology or whether discrepant self-other perceptions constitute a risk for the development of psychopathology above and beyond initial levels of psychopathology.

To address these issues, this study examined discrepant perceptions of dyadic relationships between adolescents and their partners (i.e., mothers, best friends) while controlling for cross-sectional associations between discrepant perceptions and psychopathology as well as for main effects of relationship perceptions on growth in psychopathology using a three-wave longitudinal design. In addition, a distinction was made between the absolute level of disagreement and the direction of disagreement. Overall, the results did not support the hypothesis that discrepant perceptions of dyadic relationships contribute to psychopathology. Instead, the results rather suggest that it is more important for adolescents to hold positive perceptions of close relationships than to agree with partners on the quality of the relationship. 
Table 3 Perceptions of warmth and adolescents' discrepant perceptions of warmth predicting growth curves of aggression and depression from grade 7 to grade 9

\begin{tabular}{llll} 
Depression & & & \\
\hline Intercept & & & Slope \\
\cline { 4 - 5 }$B$ & $S E B$ & & $S E B$
\end{tabular}

\begin{tabular}{|c|c|c|c|}
\hline \multicolumn{4}{|c|}{ Aggression } \\
\hline \multicolumn{2}{|c|}{ Intercept } & \multicolumn{2}{|c|}{ Slope } \\
\hline$B$ & $S E B$ & $B$ & $S E B$ \\
\hline
\end{tabular}

Model 1: adolescent-best friend disagreement

\begin{tabular}{|c|c|c|c|c|c|c|c|c|}
\hline Warmth AB & -.13 & $.05 * *$ & .05 & .03 & .05 & .04 & -.03 & $.02 *$ \\
\hline Warmth BA & -.02 & .05 & .01 & .03 & -.04 & .04 & .01 & .02 \\
\hline Absolute level & .05 & .05 & .02 & .04 & .09 & $.04 *$ & -.02 & .01 \\
\hline Direction & -.01 & .07 & .04 & .04 & -.04 & .06 & .02 & .02 \\
\hline Absolute $\times$ direction & - & - & - & - & - & - & - & - \\
\hline \multicolumn{9}{|c|}{ Model 2: adolescent-mother disagreement } \\
\hline Warmth AM & -.23 & $.11^{*}$ & .02 & .44 & -.07 & .05 & .01 & .02 \\
\hline Warmth MA & -.06 & .11 & .03 & .05 & -.10 & $.05^{*}$ & .01 & .02 \\
\hline Absolute level & -.02 & .11 & .04 & .05 & -.04 & .05 & .00 & .02 \\
\hline Direction & .01 & .10 & -.02 & .05 & -.02 & .06 & -.02 & .02 \\
\hline Absolute $\times$ direction & - & - & - & - & - & - & - & - \\
\hline
\end{tabular}

Absolute level, Absolute strength of disagreement; Direction, Overestimation of adolescent relative to partner (1) versus underestimation of adolescent relative to partner (0); AB, Adolescents' reports about relationship with best friend; BA, Best friends' reports about relationship with adolescent; AM, Adolescents' reports about relationship with mother; MA, Mothers' reports about relationship with adolescent. Gender and SES were controlled for

$* p \leq .05 ; * * p \leq .01$ (two-tailed)

Discrepant perceptions did not predict growth in psychopathology. We only found absolute levels of disagreement between adolescents and their best friends to be associated with baseline levels of aggression. This suggests that aggressive adolescents disagree more with their best friends in perceptions of warmth than non-aggressive adolescents. Aggression may be related to poor communication, which may cause discrepancies in perceptions of warmth between friends (Barker et al. 2007).

More support was found for the importance for adolescents to hold positive perceptions of close relationships, irrespective of the level of disagreement in perceptions relative to partners. Higher perceptions of warmth from mothers and friends predicted lower levels of symptoms of depression at baseline. In addition, higher perceptions of warmth in relationships with best friends predicted declines in aggression over time.

There was limited support for partners' perceptions of warmth predicting psychopathology. Only mothers' perceptions of warmth were associated with baseline levels of aggression. Given the assessment of depressive symptoms were based on adolescents' self-reports and the assessment of aggression on mothers' reports, these findings could reflect same-source same-method variance.

Although it was not possible to assess the accuracy of adolescent perceptions, the current results do not seem to support theories asserting that discrepant self or self-other perceptions in the social domain predict growth in psychopathology. First, the results challenged the idea that positively-biased self-other perceptions may have a "dark side" (Baumeister et al. 1996) or that there is an optimal range of positive self-other illusions (Baumeister 1989). Baumeister (1989) has posited that mild self-enhancement or positive self-other illusions are adaptive whereas more extreme illusions are maladaptive. Although half of the current sample consisted of adolescents at risk of aggression, it is possible that (sub-) clinical samples are needed to capture the maladaptive effects of more extreme illusions. Second, the findings were also incongruent with the idea that negatively-biased self-other perceptions present a cognitive vulnerability factor for the development of depression (Jacobs et al. 2008) but again different results may be obtained in (sub-) clinical samples. Third, the hypothesis derived from self-verification theory (Swann 1983), stating that biased self-other perceptions predict psychological distress irrespective of whether these selfother perceptions are inflated or deflated, was also not supported by the data.

Although the study did not include measures of positive adjustment, it could be that positive illusions of (dyadic) self-other relationships are developmentally adaptive rather than maladaptive (Kistner et al. 2007; Taylor and Brown 1988, 1994; Taylor et al. 2003). Taylor and Brown (1988, 1994) have suggested that individuals holding (overly) 
positive perceptions of self-other relationships may experience positive feelings about themselves and others, and are more likely to hold positive attitudes. Our finding that high levels of perceived warmth in relationships with best friends predicted declines in aggression may support this assumption. Previous research on social acceptance in middle childhood has found adaptive effects of positive illusions of peer acceptance on self-worth and peer acceptance 6 months later (Kistner et al. 2007). Increases in self-worth resulting from high perceptions of warmth in relationships with mothers and friends, whether accurate or not, could perhaps explain why no maladaptive effects on aggression and depressive symptoms were found in the current study. Future research is needed that includes a wider range of adaptive and maladaptive outcomes to obtain a more complete picture of possible mediating and compensating effects to fully understand the consequences of biased perceptions for children's development.

Another explanation for the lack of prospective effects of discrepant relationship perceptions on psychopathology in the current study could be that disagreements between mothers and adolescents reflect a normal tendency in this age period. Discrepant perceptions of warmth between adolescents and their parents may be a natural consequence of a renegotiation of family relationships as part of the adolescents' separation-individuation process, and therefore may not be predictive of symptoms of psychopathology (Feinberg et al. 2000; Reidler and Swenson 2012; Sher-Censor et al. 2012). Conversely, incongruent perceptions with best friends may reflect ignorance or misinterpretations of social feedback of the best friend and as such contribute to developmental problems over time. However, limited support was found for these ideas. Indeed, we found that discrepant perceptions between adolescents and their mothers did not predict changes in psychopathology over time, but neither did discrepant perceptions between adolescents and their best friends predict changes in psychopathology.

\section{Implications for Clinical Practice}

Informant discrepancies in the assessment of symptoms of child psychopathology and related constructs (e.g., social functioning) are common in clinical practice. Given associations of biased self and self-other perceptions of children and adolescents (relative to the reports of others) with symptoms of psychopathology, it has been suggested that the correction of children's and adolescents' biased perceptions may be an important treatment goal in clinical practice. However, in view of the mixed findings and the limitations of previous research (discussed above) and the findings of the present study, there is currently no solid base to consider discrepant perceptions of self-other relationships of children and adolescents, relative to partners, a risk for the development of psychopathology.

A cautious conclusion, suggested by the current results, is that practitioners should be more worried about low perceptions of children and adolescents of relationships with parents (i.e., mothers) and best friends than about discrepancies in perceptions. Depressive symptoms were associated with lower perceptions of warmth or support in dyadic relationships. Moreover, low perceived support from best friends (e.g., my friend cares little for me) added to the prediction of growth in aggression. However, research in clinical samples is needed to find out whether correction of discrepant perceptions of close relationships of adolescents should or should not be a treatment goal in clinical practice.

Strengths, Limitations, and Suggestions for Future Research

The present study has several strengths that are worth mentioning. To our knowledge, this study was the first to examine the developmental consequences of discrepant perceptions of close (dyadic) relationships of young adolescents in relatively large samples of mother-adolescent dyads and best friend dyads. A longitudinal approach was employed that controlled for concurrent associations of discrepant relationship perceptions with aggression and symptoms of depression. Moreover, we examined discrepancies taking into account main effects of perceptions on the outcomes.

However, there are also several limitations that need to be noted for a correct interpretation of the results. First, there is no objective or 'gold' (absolute) standard to assess the quality of close, dyadic relationships. Consistent with other research in this area, biased perceptions of adolescents were therefore conceptualized as the incongruence between the perceptions of the adolescent and the relationship partner (i.e., mothers, best friends).

Because it was not possible to establish whether discrepant perceptions reflect inaccurate perceptions of the adolescent or inaccurate perceptions of the partner or both, we might have found limited significant effects on aggression and depressive symptoms. Second and related to the issue above concerning the accuracy of perceptions, it should be noted that relationships perceptions of the partners were not controlled for aggression and depressive symptoms of partners. Third, due to computational problems when using the three different types of discrepancy variables, we were not able to examine changes in discrepant perceptions and therefore could not test whether changes in discrepant perceptions were associated with changes in symptoms of psychopathology.

In addition to addressing the limitations discussed above, it would be interesting for future research to include other types 
of dyadic relationships, for instance father-child or sibling relationships, or to examine multiple friendship relationships. The examination of multiple friendship relationships can provide important insights in the developmental consequences of systematic over- or underestimations of the qualities of friendship relationships. Systematic over- or underestimations of self-other perceptions may be less related to features of the specific relationship or the interaction partner than over- or underestimations of the quality of specific relationships. Therefore, systematic over- or underestimations may constitute a better indicator of "real" bias in the self-other perceptions of adolescents, and hence be a better predictor of problematic development.

\section{Conclusion}

This longitudinal study did not support the notion that discrepant perceptions of self-other relationships in dyadic relationships constitute a risk for the development of psychopathology (i.e., symptoms of depression and aggression) in early adolescence. The results rather suggest that it is more important for young adolescents to hold positive perceptions of close relationships than to agree with partners on the quality of the relationship. Longitudinal research that examines associations between changes in discrepant relationship perceptions and changes in symptoms of psychopathology is needed to confirm the results of this study using a more stringent design. Moreover, longitudinal research in clinical samples is warranted.

Acknowledgments This research was financially supported by supported by main grants from the Netherlands Organisation for Scientific Research (GB-MAGW 480-03-005), and Stichting Achmea Slachtoffer en Samenleving (SASS), the National Initiative Brain and Cognition (Grant 056-35-012), and various other grants from the Netherlands Organisation for Scientific Research, the VU University of Amsterdam and the Utrecht University.

Author contributions JS conceived of the study, performed the statistical analyses, and drafted the manuscript; PvL participated in the design of the longitudinal study, provided help with statistical analyses, and helped to draft the manuscript; SB participated in the design of the longitudinal study, advised on the statistical analyses, and gave feedback on the final versions of the manuscript; WM participated in the design of the longitudinal study and coordination, and gave feedback on the final versions of the manuscript; HK participated in the design of the longitudinal study and coordination, and helped to draft the manuscript; All authors read and approved the final manuscript.

\section{References}

Achenbach, T. M. (1991). Manual for the child behavior checklist/418 and 1991 profile. Burlington: University of Vermont, Department of Psychiatry.
Barker, E., Bornstein, M., Putnick, D., Hendricks, C., \& Suwalsky, J. D. (2007). Adolescent-mother agreement about adolescent problem behaviors: Direction and predictors of disagreement. Journal of Youth and Adolescence, 36, 950-962. doi:10.1007/ s10964-006-9164-0.

Baumeister, R. F. (1989). The optimal margin of illusion. Journal of Social and Clinical Psychology, 8(2), 176-189. doi:10.1521/ jscp.1989.8.2.176.

Baumeister, R. F., Smart, L., \& Boden, J. M. (1996). Relation of threatened egotism to violence and aggression: The dark side of high self-esteem. Psychological Review, 103(1), 5-33. doi:10. 1037/0033-295x.103.1.5.

Beck, A. T. (1967). Depression: Clinical, experimental, and theoretical aspects. New York: Harper and Row.

Brendgen, M., Vitaro, F., Turgeon, L., Poulin, F., \& Wanner, B. (2004). Is there a dark side of positive illusions? Overestimation of social competence and subsequent adjustment in aggressive and nonaggressive children. Journal of Abnormal Child Psychology, 32(3), 305-320. doi:10.1023/B:JACP.0000026144.08470.cd.

Cole, D. A., Martin, J. M., Peeke, L. G., Seroczynski, A. D., \& Hoffman, K. (1998). Are cognitive errors of underestimation predictive or reflective of depressive symptoms in children: A longitudinal study. Journal of Abnormal Psychology, 107, 481-496. doi:10.1037/0021-843x.107.3.481.

David, C., \& Kistner, J. (2000). Do positive self-perceptions have a "dark side"? Examination of the link between perceptual bias and aggression. Journal of Abnormal Child Psychology, 28(4), 327-337. doi:10.1023/a:1005164925300.

De Groot, A., Koot, H. M., \& Verhulst, F. C. (1994). Cross-cultural generalizability of the child behavior checklist cross-informant syndromes. Psychological Assessment, 6(3), 225.

De Los Reyes, A. (2011). Introduction to the special section: More than measurement error: Discovering meaning behind informant discrepancies in clinical assessments of children and adolescents. Journal of Clinical Child and Adolescent Psychology, 40(1), 1-9. doi:10.1080/15374416.2011.533405.

De Los Reyes, A., \& Kazdin, A. E. (2005). Informant discrepancies in the assessment of childhood: A critical review, theoretical framework, and recommendations for further study. Psychological Bulletin, 131(4), 483-509. doi:10.1037/0033-2909.131.4.483.

Defoe, I. N., Keijsers, L., Hawk, S. T., Branje, S., Dubas, J. S., Buist, K., et al. (2013). Siblings versus parents and friends: longitudinal linkages to adolescent externalizing problems. Journal of Child Psychology and Psychiatry, 54(8), 881-889.

DuBois, D. L., \& Silverthorn, N. (2004). Bias in self-perceptions and internalizing and externalizing problems in adjustment during early adolescence: A prospective investigation. Journal of Clinical Child and Adolescent Psychology, 33(2), 373-381. doi:10.1207/s15374424jccp3302_19.

Edens, J. F., Cavell, T. A., \& Hughes, J. N. (1999). The self-systems of aggressive children: A cluster-analytic investigation. Journal of Child Psychology and Psychiatry, 40(3), 441-453.

Ehrlich, K. B., Cassidy, J., Lejuez, C. W., \& Daughters, S. B. (2013). Discrepancies about adolescent relationships as a function of informant attachment and depressive symptoms. Journal of Research on Adolescence. doi:10.1111/jora.12057.

Ekornås, B., Heimann, M., Tjus, T., Heyerdahl, S., \& Lundervold, A. J. (2011). Primary school children's peer relationships: Discrepancies in self-perceived social acceptance in children with emotional or behavioral disorders. Journal of Social and Clinical Psychology, 30(6), 570-582. doi:10.1521/jscp.2011.30.6.570.

Feinberg, M. E., Howe, G. W., Reiss, D., \& Hetherington, E. M. (2000). Relationship between perceptual differences of parenting and adolescent antisocial behavior and depressive symptoms. Journal of Family Psychology, 14(4), 531-555. doi:10.1037/ 0893-3200.14.4.531. 
Furman, W., \& Buhrmester, D. (1985). Children's perceptions of the personal relationships in their social networks. Developmental Psychology, 21, 1016-1024.

Gaylord, N. K., Kitzmann, K. M., \& Coleman, J. K. (2003). Parents' and children's perceptions of parental behavior: Associations with children's psychosocial adjustment in the classroom. Parenting, 3(1), 23-47. doi:10.1207/s15327922par0301_02.

Guion, K., Mrug, S., \& Windle, M. (2009). Predictive value of informant discrepancies in reports of parenting: Relations to early adolescents' adjustment. Journal of Abnormal Child Psychology, 37(1), 17-30. doi:10.1007/s10802-008-9253-5.

Hoffman, K. B., Cole, D. A., Martin, J. M., Tram, J., \& Seroczynski, A. D. (2000). Are the discrepancies between self- and others' appraisals of competence predictive or reflective of depressive symptoms in children and adolescents: A longitudinal study Part II. Journal of Abnormal Psychology, 109(4), 651-662.

Hoza, B., Murray-Close, D., Arnold, L. E., Hinshaw, S. P., \& Hechtman, L. (2010). Time-dependent changes in positively biased self-perceptions of children with attention-deficit/hyperactivity disorder: A developmental psychopathology perspective. Development and Psychopathology, 22, 375-390. doi:10.1017/ S095457941000012X.

Hu, L., \& Bentler, P. M. (1999). Cutoff criteria for fit indexes in covariance structure analysis: Conventional criteria versus new alternatives. Structural Equation Modeling, 6(1), 1-55.

Hughes, J. N., Cavell, T. A., \& Grossman, P. B. (1997). A positive view of self: Risk or protection for aggressive children? Development and Psychopathology, 9(1), 75-94.

Jacobs, R. H., Reinecke, M. A., Gollan, J. K., \& Kane, P. (2008). Empirical evidence of cognitive vulnerability for depression among children and adolescents: A cognitive science and developmental perspective. Clinical Psychology Review, 28(5), 759-782.

Joiner, T. E., Kistner, J. A., Stellrecht, N. E., \& Merrill, K. A. (2006). On seeing clearly and thriving: Interpersonal perspicacity as adaptive (not depressive) realism (or where three theories meet). Journal of Social and Clinical Psychology, 25(5), 542-564. doi:10.1521/jscp.2006.25.5.542.

Keijsers, L., Branje, S., Hawk, S. T., Schwartz, S. J., Frijns, T., Koot, H. M., \& Meeus, W. (2012). Forbidden friends as forbidden fruit: Parental supervision of friendships, contact with deviant peers, and adolescent delinquency. Child Development, 83, 651-666.

Kistner, J. A., David-Ferdon, C. F., Repper, K. K., \& Joiner, T. E. J. (2006). Bias and accuracy of children's perceptions of peer acceptance: Prospective associations with depressive symptoms. Journal of Abnormal Child Psychology, 34(3), 336-348. doi:10. 1007/s10802-006-9028-9.

Kistner, J. A., David, C., \& Repper, K. (2007). Self-enhancement of peer acceptance: Implications for children's self-worth and interpersonal functioning. Social Development, 16(1), 24-44. doi:10.1111/j.1467-9507.2007.00370.x.

Muthén, L. K., \& Muthén, B. O. (1998-2011). Mplus (Version 6.11). Los Angeles: Muthén and Muthén.

Ohan, J. L., \& Johnston, C. (2011). Positive illusions of social competence in girls with and without ADHD. Journal of Abnormal Child Psychology, 39(4), 527-539.

Orobio de Castro, B., Brendgen, M., Van Boxtel, H., Vitaro, F., \& Schaepers, L. (2007). “Accept me, or else...": Disputed overestimation of social competence predicts increases in proactive aggression. Journal of Abnormal Child Psychology, 35(2), 165-178.

Owens, J., Goldfine, M., Evangelista, N., Hoza, B., \& Kaiser, N. (2007). A critical review of self-perceptions and the positive illusory bias in children with ADHD. Clinical Child and Family Psychology Review, 10(4), 335-351. doi:10.1007/s10567-0070027-3.

Reidler, E., \& Swenson, L. (2012). Discrepancies between youth and mothers' perceptions of their mother-child relationship quality and self-disclosure: Implications for youth- and mother-reported youth adjustment. Journal of Youth and Adolescence, 41(9), 1151-1167. doi:10.1007/s10964-012-9773-8.

Reynolds, W. M. (2002). Reynolds adolescent depression scale -2nd edition: Professional manual. Lutz: Psychological Assessment Resources.

Reynolds, W. M., \& Mazza, J. J. (1998). Reliability and validity of the reynolds adolescent depression scale with young adolescents. Journal of School Psychology, 36(3), 295-312. doi:10.1016/ S0022-4405(98)00010-7.

Scholtens, S., Diamantopoulou, S., Tillman, C. M., \& Rydell, A.-M. (2012). Effects of symptoms of ADHD, ODD, and cognitive functioning on social acceptance and the positive illusory bias in children. Journal of Attention Disorders, 16(8), 685-696. doi:10. 1177/1087054711417398.

Sher-Censor, E., Oppenheim, D., \& Sagi-Schwartz, A. (2012). Individuation of female adolescents: Relations with adolescents' perceptions of maternal behavior and with adolescent-mother discrepancies in perceptions. Journal of Adolescence, 35(2), 397-405. doi:10.1016/j.adolescence.2011.07.018.

Statistics-Netherlands. (1993). Standaard beroepenclassificatie 1992 [Standardized classification of occupations 1992. Voorburg/ Heerlen: Netherlands Central Bureau of Statistics.

Swann, W. B, Jr. (1983). Self-verification: Bringing social reality into harmony with the self. In J. Suls \& A. G. Greenwald (Eds.), Social psychological perspectives on the self (Vol. 2, pp. 33-66). Hillsdale: Erlbaum.

Taylor, S. E., \& Brown, J. D. (1988). Illusion and well-being: A social psychological perspective on mental health. Psychological Bulletin, 103(2), 193.

Taylor, S. E., \& Brown, J. D. (1994). Positive illusions and well-being revisited: Separating fact from fiction. Psychological Bulletin, 116, 21-27.

Taylor, S. E., Lerner, J. S., Sherman, D. K., Sage, R. M., \& McDowell, N. K. (2003). Portrait of the self-enhancer: Well adjusted and well liked or maladjusted and friendless? Journal of Personality and Social Psychology, 84(1), 165-176.

Van Lier, P. A. C., Frijns, T., Neumann, A., den Exter Blokland, E., Koot, H. M., \& Meeus, W. H. J. (2011). The RADAR young study: Design, description of sample, and validation of cohort assignment. Unpublished manuscript, VU University Amsterdam \& Utrecht University, The Netherlands.

Verhulst, F., Van der Ende, J., \& Koot, H. (1996). Handleiding voor de CBCL/4-18 (Manual for the CBCL/4-18). Erasmus University, Department of Child and Adolescent Psychiatry, Sophia Children's Hospital, Rotterdam.

Whitton, S. W., Larson, J. J., \& Hauser, S. T. (2008). Depressive symptoms and bias in perceived social competence among young adults. Journal of Clinical Psychology, 64(7), 791-805. doi:10.1002/jclp.20488.

Jantine L. Spilt, PhD is an assistant professor at the research division School Psychology and Child and Adolescent Development at the KU Leuven, Belgium. She received her doctorate in Social and Behavioral Sciences from the University of Amsterdam, The Netherlands, in 2010. In her research, she focuses on understanding the impact of dyadic relationships, in particular teacher-student relationships, on children's socio-emotional, behavioral, and academic development. The current study was part of her postdoctoral research at the VU University in Amsterdam, The Netherlands.

Pol A. C. Van Lier, PhD is a professor of Developmental Psychopathology at the Department of Developmental Psychology at the VU University in Amsterdam, The Netherlands. He received his doctorate from Erasmus University Rotterdam, The Netherlands, in 2002. His research interests are in the area of development of psychopathology in children, with a particular focus on social and personal influences. 
Susan J. T. Branje, PhD is a professor at the Research Centre Adolescent Development at Utrecht University. She received her cum laude doctorate in Developmental Psychology from the Radboud University Nijmegen, The Netherlands, in 2003. Her work generally focuses on understanding the developmental changes in adolescents' relationships with parents, siblings, friends, and romantic partners and the associations with development of adolescent personality and psychosocial adjustment.

Wim Meeus, $\mathbf{P h D}$ is Professor of Adolescent Development at Utrecht University, and Professor of Developmental Psychology at Tilburg University, The Netherlands. He received his doctorate in Social
Psychology from Utrecht University, The Netherlands, in 1984. His major research interests include identity and personality development, personal relationships, and psychosocial problems in adolescence.

Hans M. Koot, PhD is a professor and director of Developmental Psychology and Developmental Psychopathology at VU University Amsterdam, The Netherlands. He received his cum laude doctorate in Medicine and Health Sciences from the Erasmus University, Rotterdam, The Netherlands, in 1993. His major research interests regard the etiology, diagnostics, and intervention of emotional and behavioral problems in children and adolescents. 